\title{
Diagnostic Accuracy of a Two-Stage Sequential Screening Strategy Implemented by Community Health Workers (CHWs) to Identify Individuals with COPD in Rural India
}

\author{
Prashant Jarhyan ${ }^{1-3}$ \\ Anastasia Hutchinson ${ }^{1,2}$ \\ Rajesh Khatkar' \\ Dimple Kondal' \\ Mari Botti (D) ${ }^{2}$ \\ Dorairaj Prabhakaran 1,3,4 \\ Sailesh Mohan ${ }^{1-3}$ \\ 'Centre for Chronic Conditions and \\ Injuries (CCCl), Public Health Foundation \\ of India, Gurgaon, India; ${ }^{2}$ Institute of \\ Health Transformation, Faculty of Health, \\ Deakin University, Burwood, Melbourne, \\ Australia; ${ }^{3}$ Centre for Chronic Disease \\ Control (CCDC), Delhi, India; \\ ${ }^{4}$ Department of Epidemiology, London \\ School of Hygiene and Tropical Medicine, \\ London, UK
}

\begin{abstract}
Purpose: Undiagnosed Chronic Obstructive Pulmonary Disease (COPD) results in high morbidity, disability and mortality in India. Effective strategies for active COPD screening in community settings are needed to increase early identification, risk reduction and timely management. The objective of this study was to test the diagnostic accuracy of a sequential two-step screening strategy to detect COPD, implemented by community health workers (CHWs), among adults aged $\geq 40$ years in a rural area of North India.

Patients and Methods: Trained CHWs screened all consenting $(n=3256)$ eligible adults in two villages using the Lung Function Questionnaire (LFQ) to assess their COPD risk and conducted pocket spirometry on 268 randomly selected (132 with high risk ie LFQ score $\leq 18$ and 136 with low risk ie LFQ score $>18$ ) individuals. Subsequently, trained researchers conducted post-bronchodilator spirometry on these randomly selected individuals using a diagnostic quality spirometer and confirmed the COPD diagnosis according to the Global Initiative for Obstructive Lung Disease (GOLD) criteria $\left(\mathrm{FEV}_{1} / \mathrm{FVC}\right.$ ratio $\left.<0.7\right)$.

Results: This strategy of using LFQ followed by pocket spirometry was sensitive (78.6\%) and specific (78.8\%), with a positive predictive value of $66 \%$ and negative predictive value of $88 \%$. It could accurately detect $67 \%$ of GOLD Stage $1,78 \%$ of GOLD Stage $2,82 \%$ of GOLD Stage 3 and $100 \%$ of GOLD Stage 4 individuals with airflow limitation.

Conclusion: COPD can be accurately detected by trained CHWs using a simple sequential screening strategy. This can potentially contribute to accurate assessment of COPD and thus its effective management in low-resource settings.
\end{abstract}

Keywords: COPD, sensitivity and specificity, screening, community health workers, spirometry

\section{Introduction}

Chronic Obstructive Pulmonary Disease (COPD) is one of the most common causes of morbidity, disability, and mortality in India. ${ }^{1}$ It remains largely undetected due to a lack of awareness among the community and under-diagnosis in clinical practice. $^{2,3}$ Spirometry is the most reproducible, objective and a non-invasive lung function test. ${ }^{4}$ Spirometry measures the ratio of forced expiratory volume in one second $\left(\mathrm{FEV}_{1}\right)$ to the forced vital capacity (FVC) and the presence of postbronchodilator $\mathrm{FEV}_{1} / \mathrm{FVC}<0.7$ confirms the presence of airflow limitation which is required for the diagnosis of COPD. ${ }^{4}$ There is a shortage of skilled medical
Correspondence: Sailesh Mohan

Public Health Foundation of India, Plot 47, Sector-44, Gurgaon, 122002, India

Tel +9| $|24478| 400$

Fax +9| 124-478|60।

Email smohan@phfi.org 
personnel to conduct spirometry in primary care settings in India, resulting in under-diagnosis, thus impeding timely management of COPD. ${ }^{5}$

Screening early for COPD can facilitate the early institution of pharmacological treatment, higher smoking cessation rates, greater uptake of vaccination against influenza and pneumococcal pneumonia, participation in pulmonary rehabilitation, and improved identification and better management of comorbidities. ${ }^{6,7}$ Screening questionnaires and simple devices like pocket spirometers have been successfully used for screening and detecting hidden COPD cases in primary care settings of high-income countries. ${ }^{8-11}$ Pocket spirometers measure $\mathrm{FEV}_{1} / \mathrm{FEV}_{6}$ ratio to assess the airflow limitation instead of FEV1/FVC ratio which is measured by a diagnostic quality spirometer. ${ }^{12}$ The $\mathrm{FEV}_{6}$ has been identified as a valid estimate of FVC and is easier to perform consistently outside of a controlled laboratory environment and therefore can be used for screening of COPD among those with high-risk. ${ }^{12}$ In low and middle-income countries (LMICs) like India, the COPD burden is rising and constrained health infrastructure, including limited skilled human resources, impede the implementation of effective COPD screening and detection programs, especially within rural primary health care settings. Training and involving community health workers (CHWs), who comprise the largest health workforce in rural settings in India, in screening may provide an effective means of early detection. ${ }^{13,14}$ Thus, this study aimed to test the diagnostic accuracy of a sequential, twostep screening strategy implemented by CHWs, using the Lung Function Questionnaire (LFQ) and pocket spirometry (PS) to detect individuals with COPD in rural India.

\section{Patients and Methods}

A prospective diagnostic accuracy study was nested within one site (Sonipat, Haryana, India) of a large communitybased research project entitled "UDAY". "UDAY" is a comprehensive diabetes and hypertension prevention and management program in India; the detailed methodology has been published previously. ${ }^{15}$ Briefly, UDAY was implemented in a population of about 100,000 each in rural and urban subsites in north India (Sonipat district in Haryana state) and south India (Visakhapatnam district in Andhra Pradesh state). In each rural and urban subsite, trained project staff referred to as CHWs (1 CHW per 5000 population) selected from the same area, conducted surveys and screened adults aged $\geq 30$ years for the presence of diabetes and hypertension, subsequently linking those at high risk or with diabetes and/or hypertension to the healthcare system. CHWs also provided tailored health education to patients regarding non-pharmacological management of diabetes and hypertension and educated the general population about modification/reduction of risk factors.

\section{Study Population}

In this study, we included individuals aged $\geq 40$ years from the two largest villages selected by purposive sampling from the UDAY rural area in north India. Individuals with a cognitive impairment limiting their ability to answer the study questions and those who were bedridden or terminally ill were excluded.

\section{Definitions and Study Tools}

COPD was defined using the Global Initiative for Obstructive Lung Disease (GOLD) criteria, ie, the forced expiratory volume in 1 second $\left(\mathrm{FEV}_{1}\right)$ and its ratio to Forced Vital Capacity (FVC), with the $\mathrm{FEV}_{1} / \mathrm{FVC}<0.7$ post-administration of a bronchodilator. ${ }^{4}$ Severity of airflow limitation was defined using GOLD criteria, ie, postbronchodilator $\mathrm{FEV}_{1} \geq 80 \%$ predicted as mild, $50 \% \leq$ to $<80 \%$ predicted as moderate, $30 \% \leq$ to $<50 \%$ predicted as severe and $<30 \%$ predicted as very severe. ${ }^{4}$ For screening, we used the Lung Function Questionnaire (LFQ), which is a case-finding tool to detect individuals for further confirmatory evaluation using spirometry. ${ }^{16}$ Two independent interpreters translated the LFQ into the local Hindi language. The two versions were combined by the first author and the translated version was back-translated by two independent research professionals. The Hindi language version was tested for face-validity by administering the questionnaire to $10 \mathrm{COPD}$ patients in the community and was finalized in consultation with a local chest physician and a general physician. CHWs used the COPD-6 (Vitalograph model 4000) PS to measure $\mathrm{FEV}_{1}$, forced expiratory volume in 6 seconds $\left(\mathrm{FEV}_{6}\right)$, and $\mathrm{FEV}_{1} / \mathrm{FEV}_{6}$ ratio. We used maximum values for $\mathrm{FEV}_{1}$ and $\mathrm{FEV}_{6}$ obtained from the repeated forced expiratory manoeuvres to measure the $\mathrm{FEV}_{1} / \mathrm{FEV}_{6}$ ratios and a ratio of $\mathrm{FEV}_{1}$ $/ \mathrm{FEV}_{6}<0.7$ obtained by the pocket spirometry was considered as the criteria for airflow limitation. ${ }^{17}$ We measured the acceptability of the forced expiratory manoeuvre by using the GOLD criteria (ie the two highest values of FVC and $\mathrm{FEV}_{1}$ from acceptable manoeuvres are within $\left.0.15 \mathrm{~L}\right) .{ }^{4}$ Trained researchers used the NDD EasyOne portable spirometers (EasyOne, NDD Medical Technologies, Zurich, 
Switzerland) as the diagnostic quality spirometer which meets American Thoracic Society (ATS)/European Respiratory Society (ERS) standards (Website:www. ndd.ch).

\section{Training of Community Health Workers}

Twenty CHWs were trained to administer the LFQ and conducting PS. Each CHW participated in a pre-testing session with at least 10 participants under the supervision of the research staff. CHWs were shown a video of PS recommended by the manufacturers. During the training, the emphasis was placed on how to coach and encourage the participant to perform an acceptable forced expiratory manoeuvre and to recognize an unacceptable forced expiratory manoeuvre. Additionally, CHWs were trained to identify people with any contraindication to performing the spirometry using a checklist. After the training, eight out of 20 CHWs were selected to conduct the PS after ascertaining their ability to use the PS.

\section{Study Procedures}

CHWs screened all eligible individuals who consented to take part in the study using a paper-based version of the LFQ in participants' homes during September and October 2017. The information from the LFQ was entered into a Microsoft Excel spreadsheet by a data entry operator and data were checked for any inconsistencies by a research staff not involved in the screening process. Primary and secondary sample lists of 250 randomly selected participants, each with an LFQ score of $\leq 18$ or $>18$ were invited for assessing their height and weight at nearby community halls of their respective villages. Height was measured in $\mathrm{cm}$ to the nearest $0.1 \mathrm{~cm}$ with a portable stadiometer and weight was measured to the nearest $100 \mathrm{gm}$ with a reliable weighing scale in light clothes with no shoes in a standardised manner. After ruling out contraindications for spirometry using a checklist, PS was conducted by CHWs. The trained researchers then conducted pre and postbronchodilation (BD) spirometry using the diagnostic quality spirometers. Study participants rested for 15-20 minutes between PS and diagnostic spirometry and also between pre and post-BD spirometry. CHWs performing PS were blinded to the LFQ scores and trained researchers were blinded to the LFQ scores and the PS results. Standards for Reporting Diagnostic accuracy studies (STARD) were used to report the findings of the study (Table S1). ${ }^{18}$

\section{Statistical Analysis}

The sample size calculation was based on the assumption that a random sample of 130 participants from the positive population (LFQ score $\leq 18$ ) and 130 (LFQ score $>18$ ) from the negative population would produce an AUC of 0.75 (95\% CI: 0.63 to 0.87$).{ }^{19}$

Baseline characteristics of participants were compared using independent $t$-test and Pearson's chi-square statistics. Diagnostic accuracy was measured by determining the sensitivity, specificity, AUC, positive and negative likelihood ratios, and predictive values of the individual test (LFQ and PS) and the combined sequential strategy (PS conducted among those with LFQ score $\leq 18)$. Bland-Altman (B\&A) plots were used to describe the agreement between the two measurements of the maximum values for $\mathrm{FEV}_{1}$ obtained by PS and prebronchodilation spirometry, using the diagnostic quality spirometer and maximum values of $\mathrm{FEV}_{6}, \mathrm{FVC}$ measured respectively by the PS and pre-bronchodilation spirometry. Finally, we conducted a sensitivity analysis by measuring the diagnostic accuracy for individual CHWs, the best four performing CHWs $(n=4)$, and the worst-performing CHWs $(\mathrm{n}=4)$. All statistical analyses were conducted using the STATA software V.12 (StataCorp, College Station, TX, USA).

\section{Ethical Considerations}

The study was conducted in accordance with the Declaration of Helsinki and was approved by the Institutional Ethics Committees of Deakin University and the Public Health Foundation of India. The CHWs obtained written and informed consent from all study participants. Participants diagnosed with COPD were referred to the nearest public health centre for further evaluation and management and were provided risk reduction advice for their risk factors.

\section{Results}

The flow of participants who completed the LFQ and subsequently the pocket spirometry and the pre and postbronchodilator spirometry is shown in Figure 1. For screening, 3256 eligible individuals completed the LFQ, 268 participated in PS and 251 participants completed the post-bronchodilation spirometry.(Figure 1). Twelve participants did not want to undergo further spirometry and lung function test results for five participants was not included in the analysis due to incompleteness of the 


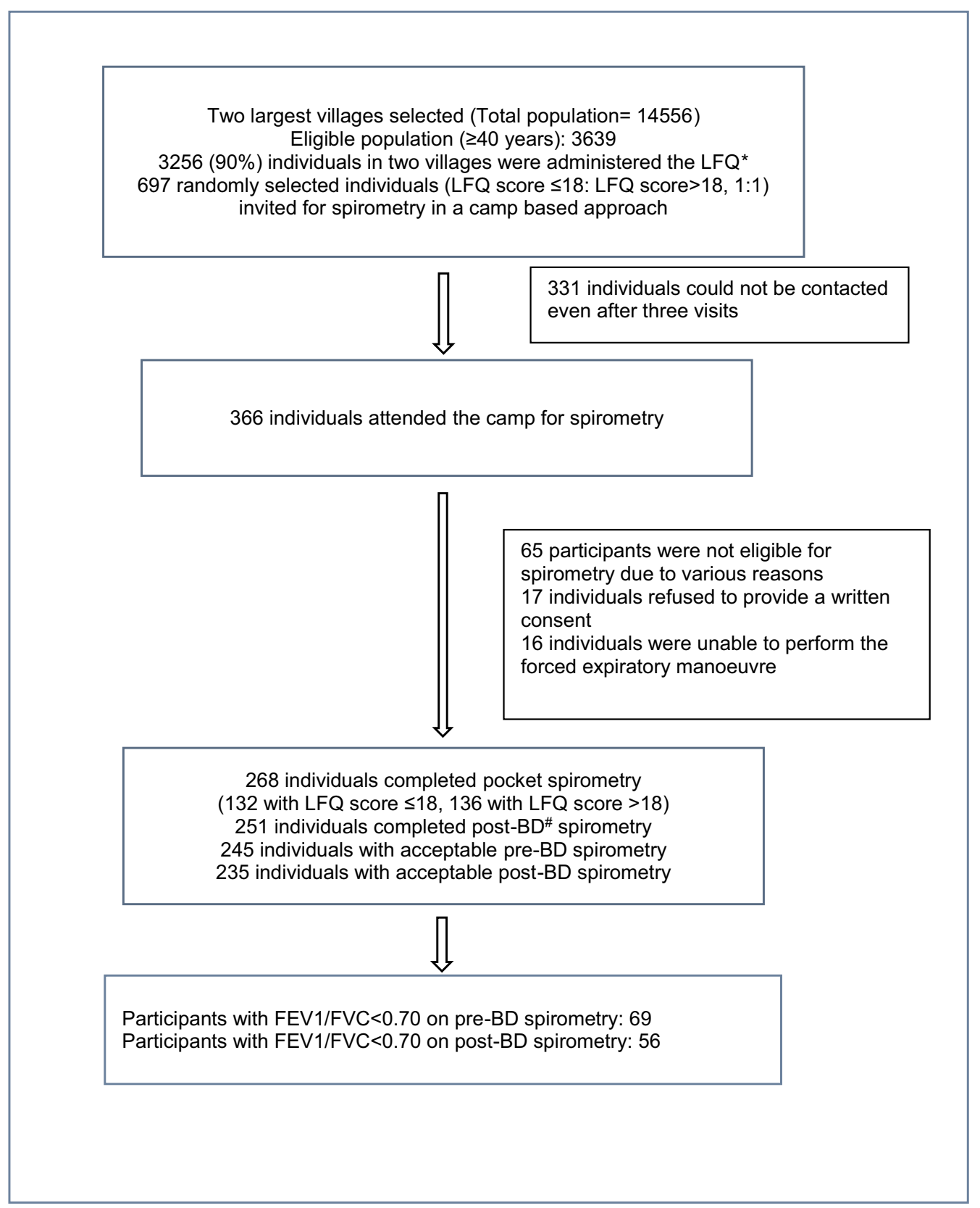

Figure I Participant flow diagram.

Abbreviations: LFQ, Lung Function Questionnaire; BD, bronchodilation.

data (results from only one forced expiratory manoeuvre were available for these five participants).

There were no significant differences in the mean age, gender distribution, and proportion of those who were able to read and understand the LFQ between the participants who were randomly selected and those not selected for spirometry. The mean LFQ score of the participants who participated in spirometry was slightly lower than the total LFQ score of the participants who were not selected for spirometry (Table 1).
There were no significant differences $(>150 \mathrm{~mL})$ in the group mean values for $\mathrm{FEV}_{1}$ and $\mathrm{FEV}_{6}$ volumes between the three acceptable blows recorded using the PS (Table 2). However, a difference of $>150 \mathrm{~mL}$ between an individual participant's two highest $\mathrm{FEV}_{1}$ volumes was present in $60(22.4 \%)$ measurements and a difference of $>150 \mathrm{~mL}$ between the two highest $\mathrm{FEV}_{6}$ volumes was present in 92 (34.3\%) measurements.

The mean $( \pm \mathrm{SD})$ difference between $\mathrm{FEV}_{1}$ and between $\mathrm{FEV}_{6}$ and FVC measured by PS and pre-BD spirometry 
Table I Comparison of Demographic Characteristics of the Study Participants ( $N=3256)$

\begin{tabular}{|c|c|c|c|}
\hline Variables & $\begin{array}{l}\text { Participants } \\
\text { without } \\
\text { Spirometry } \\
(n=2988)\end{array}$ & $\begin{array}{l}\text { Participants Randomly } \\
\text { Selected for Spirometry } \\
(n=268)\end{array}$ & $p$-value \\
\hline Mean age in years $( \pm S D)$ & $56.5( \pm 12.2)$ & $56.7( \pm 10.4)$ & 0.83 \\
\hline Men, n (\%) & $1233(41.3)$ & $123(45.9)$ & 0.14 \\
\hline Able to read and understand LFQ*, n (\%) & $1323(44.3)$ & $199(48.1)$ & 0.22 \\
\hline \multicolumn{4}{|l|}{ How often do you cough up mucus?, n (\%) } \\
\hline Never & 1980 (66.3\%) & $163(60.8 \%)$ & 0.15 \\
\hline Rarely & $327(10.9 \%)$ & $35(13.1 \%)$ & \\
\hline Sometimes & $369(12.4 \%)$ & $33(12.3 \%)$ & \\
\hline Often & 149 (5.0\%) & 14 (5.3\%) & \\
\hline Very often & $163(5.5 \%)$ & $23(8.7 \%)$ & \\
\hline \multicolumn{4}{|c|}{$\begin{array}{l}\text { How often does your chest sound noisy (wheezy, whistling, rattling) when you } \\
\text { breathe?, n (\%) }\end{array}$} \\
\hline Never & 2301 (77.0\%) & $202(75.4 \%)$ & 0.48 \\
\hline Rarely & $247(8.3 \%)$ & $20(7.5 \%)$ & \\
\hline Sometimes & $220(7.4 \%)$ & $28(10.5 \%)$ & \\
\hline Often & $133(4.5 \%)$ & II (4.I\%) & \\
\hline Very often & 87 (2.9\%) & $7(2.6 \%)$ & \\
\hline \multicolumn{4}{|c|}{$\begin{array}{l}\text { How often do you experience shortness of breath during physical activity (walking } \\
\text { up a flight of stairs or walking up an incline without stopping to rest)?, n (\%) }\end{array}$} \\
\hline Never & 1544 (5I.7\%) & $123(45.9 \%)$ & 0.16 \\
\hline Rarely & $268(9.0 \%)$ & $21(7.8 \%)$ & \\
\hline Sometimes & 444 (14.9\%) & $51(19.0 \%)$ & \\
\hline Often & 395 (13.2\%) & 35 (13.1\%) & \\
\hline Very often & 337 (11.3\%) & 38 (I4.2\%) & \\
\hline \multicolumn{4}{|l|}{ How many years have you smoked?, n (\%) } \\
\hline Never smoked & $1697(56.8 \%)$ & $143(53.4 \%)$ & 0.09 \\
\hline$\leq 10$ years & $237(8.0 \%)$ & I4 (5.2\%) & \\
\hline II-20 years & $254(8.5 \%)$ & $25(9.3 \%)$ & \\
\hline $21-30$ years & $174(5.8 \%)$ & $13(4.9 \%)$ & \\
\hline$>30$ years & $626(21.0 \%)$ & $73(27.2 \%)$ & \\
\hline Mean LFQ score $( \pm S D)$ & $19.1( \pm 4.0)$ & $18.4( \pm 3.9)$ & 0.01 \\
\hline
\end{tabular}

Notes: *The LFQ items/questions are reproduced from Hanania NA, Mannino DM, Yawn BP, et al. Predicting risk of airflow obstruction in primary care: Validation of the lung function questionnaire (LFQ). Respiratory Medicine. 2010;104(8):।160-1170. Copyright 2010 Elsevier Ltd. All rights reserved. ${ }^{16}$

Abbreviation: LFQ, Lung Function Questionnaire.

Table 2 Comparison of Lung Function Parameters $\left(\mathrm{FEV}_{1}\right.$ and $\left.\mathrm{FEV}_{6}\right)$ of Participants Obtained from the Three Best Forced Expiratory Manoeuvres on the Pocket Spirometer

\begin{tabular}{|l|l|l|l|l|l|l|}
\hline $\begin{array}{l}\text { Parameters } \\
\mathbf{N}=\mathbf{2 6 8}\end{array}$ & $\begin{array}{l}\text { FEV } \\
\text { Blow I }\end{array}$ & $\begin{array}{l}\text { FEV } \\
\text { Blow 2 }\end{array}$ & $\begin{array}{l}\text { FEV } \\
\text { Blow 3 }\end{array}$ & $\begin{array}{l}\text { FEV }_{\mathbf{6}} \\
\text { Blow I }\end{array}$ & $\begin{array}{l}\text { FEV }_{\mathbf{6}} \\
\text { Blow 2 }^{\text {2 }}\end{array}$ & $\begin{array}{l}\text { FEV }_{\mathbf{6}} \\
\text { Blow 3 }\end{array}$ \\
\hline Mean & 1.57 & 1.63 & 1.65 & 2.14 & 2.26 & 2.23 \\
Standard deviation & 0.68 & 0.67 & 0.67 & 0.83 & 0.90 & 0.80 \\
Range & $0.38-3.77$ & $0.42-3.86$ & $0.39-3.95$ & $0.57-4.81$ & $0.51-7.58$ & $0.66-4.71$ \\
\hline
\end{tabular}


respectively was $105 \mathrm{~mL}(95 \% \mathrm{CI}: 81-130 \mathrm{~mL}) \mathrm{mL}$ and $156 \mathrm{~mL}$ (95\% CI: 102-211 mL) respectively (Table 4) and $67 \%$ of $\mathrm{FEV}_{1}$ values measured by PS had a difference of fewer than $150 \mathrm{~mL}$ as compared to $\mathrm{FEV}_{1}$ measured by preBD spirometry(Table 3).

The prevalence of COPD in the study population was 23.8\% (95\% CI: 18.3-28.8). Among participants who underwent pre-BD diagnostic level spirometry with acceptable manoeuvres $(\mathrm{n}=235), 69(29 \%)$ had an airflow limitation $\left(\mathrm{FEV}_{1} / \mathrm{FVC}<0.70\right)$. Based on post-BD diagnostic level spirometry with acceptable manoeuvres $(\mathrm{n}=235), 56$ (24\%) met criteria for COPD diagnosis with 9 participants (16\%) diagnosed with GOLD Stage 1, 32 (57\%) with Stage 2, 12 (21\%) with Stage 3 and 3 (5\%) with Stage 4 COPD severity.

The sensitivity of the LFQ was higher $(75 \%, 95 \% \mathrm{CI}$ : $61.6 \%-85.6 \%)$ than the PS $(69.6 \%, 95 \%$ CI: $55.9 \%$ $81.2 \%)$, while the specificity of PS was higher $(81.0 \%$, 95\% CI: $74.5 \%-86.5 \%)$ than the LFQ $(55.3 \%$, 95\% CI: 47.7\%-62.7\%). The combined sequential strategy had the highest AUC and positive predictive values and positive likelihood ratios. The sequential strategy was able to detect $79 \%$ of COPD cases $(67 \%$ of GOLD Stage 1 , $78 \%$ of GOLD Stage 2, 82\% of GOLD Stage 3, and $100 \%$ of GOLD Stage 4 of airflow limitation).

The Bland-Altman plot showed fewer differences $(\mathrm{n}=6 /$ $245>2 \mathrm{SD}$ ) between the two devices when comparing $\mathrm{FEV}_{1} / \mathrm{FEV}_{6}$ ratio with the $\mathrm{FEV}_{1} / \mathrm{FVC}$ ratio (Figure 2, Panel 1).

\section{Sensitivity Analysis}

Eight CHWs conducted spirometry with the PS, one CHW was not able to conduct spirometry and was discontinued after conducting spirometry on three participants. The diagnostic accuracy of the sequential strategy increased when we restricted the analysis to the four best performing CHWs in PS [sensitivity: 92.9\% (76.5\%-99.1\%); specificity: $75.5 \%(61.7 \%-86.2 \%)$ ], as compared to the other four CHWs [sensitivity: $50.0 \%$ (23.0\%-77.0\%); specificity: 85.2\% (66.3\%-95.8\%)]. Almost all CHWs except one were able to detect participants with COPD GOLD severity stages 3 and 4 (Supplementary Table S2).

\section{Discussion}

Early detection of COPD is necessary to accurately determine the actual disease burden and initiate appropriate therapies to reduce mortality, limit disability, and improve quality of life. In this study, we found that a sequential screening strategy implemented by CHWs using an LFQ followed by PS was highly sensitive and specific in detecting adults with COPD in a rural community of North India. Notably, this sequential strategy was able to detect over four-fifths of severe and very severe (GOLD Stage 3 and GOLD Stage 4) COPD cases.

Most studies evaluating COPD screening using a questionnaire in primary care have been conducted in high-income countries. ${ }^{8-11} \mathrm{~A}$ recent systematic review of the evidence regarding COPD screening reported that the COPD Diagnostic Questionnaire (CDQ) was the best screening questionnaire. ${ }^{20}$ However, we used the LFQ as a screening tool because LFQ includes a question about smoking in general as compared to other questionnaires including CDQ that specifically ask about cigarette smoking. As other forms of tobacco smoking are common in the Indian population, the LFQ was deemed to be a more appropriate screening questionnaire for our study. We found that the diagnostic accuracy values of LFQ and preBD PS in measuring FEV1/FEV6 in our study were similar to values reported by the use of other screening

Table 3 Diagnostic Performance of the Lung Function Questionnaire (LFQ), Pocket Spirometry (PS) and the Combined Strategy (LFQ Followed by the PS) Compared to the Post-Bronchodilation Spirometry $(n=235)$

\begin{tabular}{|l|l|l|l|}
\hline Parameters & Lung Function Questionnaire & Pocket Spirometry & Combined \\
\hline Prevalence, \% (95\% Cl) & $24(19.0-29.8)$ & $24(19.0-29.8)$ & $34.0(26.0-43.6)$ \\
Sensitivity, \% (95\% Cl) & $75.0(61.6-85.6)$ & $69.6(55.9-81.2)$ & $78.6(63.2-89.7)$ \\
Specificity, \% (95\% Cl) & $55.3(47.7-62.7)$ & $81.0(74.5-86.5)$ & $78.8(68.2-87.1)$ \\
Area under the receiver operating characteristics curve & $0.65(0.58-0.72)$ & $0.75(0.69-0.82)$ & $0.79(0.7 I-0.86)$ \\
Likelihood ratio (+) & $1.68(1.34-2.10)$ & $3.67(2.59-5.19)$ & $3.70(2.36-5.80)$ \\
Likelihood ratio (-) & $0.45(0.28-0.73)$ & $0.38(0.25-0.56)$ & $0.27(0.15-0.49)$ \\
Odds ratio & $3.7(1.91-7.22)$ & $9.78(4.97-19.20)$ & $13.6(5.52-33.40)$ \\
Positive predictive value, \% $(95 \% \mathrm{Cl})$ & $34.4(26.1-43.6)$ & $53.4(41.4-65.2)$ & $66.0(51.2-78.8)$ \\
Negative predictive value, \% $(95 \% \mathrm{Cl})$ & $87.6(80.1-93.1)$ & $89.5(83.7-93.8)$ & $87.5(77.6-94.2)$ \\
\hline
\end{tabular}


Table 4 Comparison of Lung Function Parameters FEVI, FEV6 or FVC(L) as Measured by Pocket Spirometry, Pre-Bronchodilation and Post-Bronchodilation Gold Standard Spirometry

\begin{tabular}{|c|c|c|c|c|}
\hline \multirow[t]{2}{*}{ Lung Function Parameter } & \multirow{2}{*}{$\begin{array}{l}\text { Pocket Spirometry } \\
\text { Pre-Bronchodilator Mean } \\
(95 \% \mathrm{Cl})\end{array}$} & \multicolumn{3}{|l|}{ Gold Standard Spirometry } \\
\hline & & $\begin{array}{l}\text { Pre-Bronchodilator Mean } \\
(95 \% \mathrm{Cl})\end{array}$ & \multicolumn{2}{|c|}{$\begin{array}{l}\text { Post-Bronchodilator } \\
\text { Mean }(95 \% \mathrm{Cl})\end{array}$} \\
\hline FEV (in Liters) & $1.74(1.66-1.82)$ & $1.82(1.74-1.91)$ & \multirow{2}{*}{\multicolumn{2}{|c|}{$\begin{array}{l}1.89(1.80-1.96) \\
2.55(2.44-2.65)\end{array}$}} \\
\hline $\mathrm{FEV}_{6}$ or FVC* (in Liters) & $2.42(2.3 \mathrm{I}-2.52)$ & $2.50(2.39-2.60)$ & & \\
\hline \multicolumn{5}{|l|}{ Limits of agreement } \\
\hline Values & Limits of agreement & Mean difference & $95 \% \mathrm{Cl}$ & p-value \\
\hline PS FEVI vs Pre FEVI & -0.288 to 0.499 & 0.105 & 0.081 to 0.130 & $<0.001$ \\
\hline PS FEVI vs Post FEVI & -0.256 to 0.619 & 0.182 & 0.153 to 0.210 & 0.001 \\
\hline PS FEV6* vs Pre FVC & -0.705 to 1.017 & 0.156 & 0.102 to 0.211 & 0.007 \\
\hline PS FEV6* vs Post FVC & -0.683 to 1.124 & 0.221 & 0.162 to 0.279 & 0.434 \\
\hline PS FEVI/FEV6* vs Pre FEVI/FVC & -0.284 to 0.181 & -0.052 & -0.066 to -0.037 & 0.000 \\
\hline PS FEVI/FEV6* vs Post FEVI/FVC & -0.284 to 0.202 & -0.041 & -0.057 to -0.026 & 0.000 \\
\hline
\end{tabular}

Notes: ${ }^{*} \mathrm{FEV}_{6}$ for pocket spirometry, FVC for gold standard spirometry.

questionnaires and hand-held pulmonary function screening tests. ${ }^{20}$

A few studies have assessed the diagnostic accuracy of using a screening questionnaire followed by an assessment of lung function using pocket spirometers/flow meters.
Sichletidis et al in Greece found that a combination of the International Primary Care Airways Guidelines questionnaire (IPAG) and use of the PiKo-6 flow meter by general practitioners (GPs) had a higher sensitivity (72\%) and specificity (97\%) than individual use of the IPAG
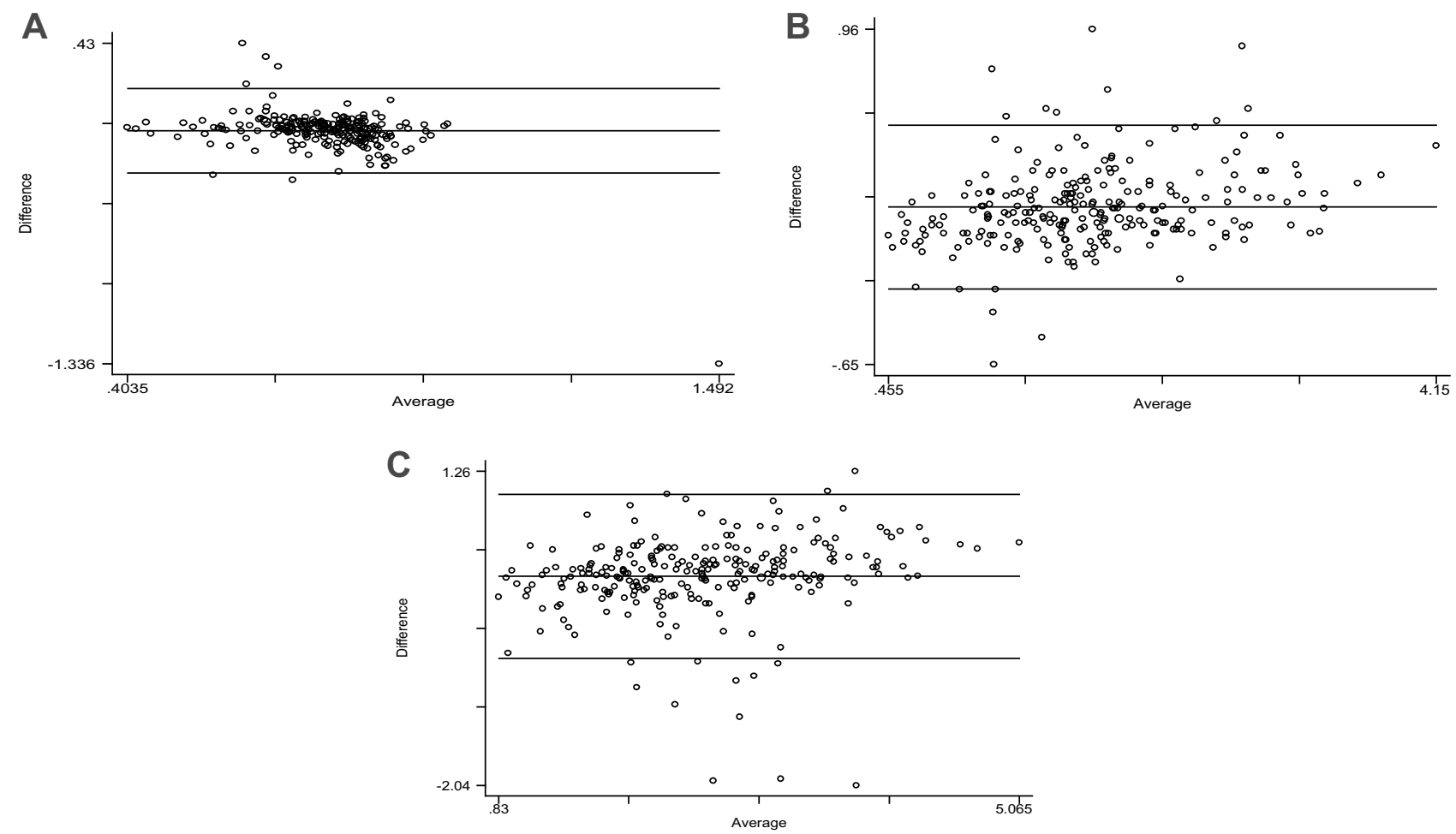

Figure 2 Bland-Altman plots comparing lung function parameters between pocket spirometry and pre-bronchodilator spirometry. (A) Bland-Altman plot comparing FEVI/ FEV6 ratio obtained from pocket spirometry with that FEVI/FVC ratio of pre-bronchodilator spirometry (B) Bland-Altman plot comparing FEV , obtained from pocket spirometry with that of pre-bronchodilator spirometry. (C) Bland-Altman plot comparing $\mathrm{FEV}_{6}$ obtained from pocket spirometry with that of FVC obtained from prebronchodilator spirometry. 
(sensitivity: $80 \%$ and specificity: $95 \%$ ) and flow meter (sensitivity: $91 \%$ and specificity: $49 \%$ ). ${ }^{21}$ The specificity of the combined tests was lower in our study $(78.8 \%)$ as compared to the study (95\%) by Sichletidis et al. ${ }^{2}$ In our study, the readings obtained for forced expiration manoeuvres ( $\mathrm{FEV}_{1}$ and $\mathrm{FVC}$ values) using diagnostic quality spirometry by trained researchers were higher than those obtained by CHWs using PS. This possibly also reflects that participants had gained experience after performing the required forced expiratory manoeuvres using the PS and that better coaching of participants by trained researchers to perform the maneuver was possible because they could see the flow-volume curves on their computer screens. This indicates that the diagnostic accuracy of the test also depends upon the skills of those performing the spirometry and the ability of participants to understand and perform the manoeuvre. Despite this, for the majority of participants, the differences between $\mathrm{FEV}_{1}$ values measured between two devices was less than $150 \mathrm{~mL}$.

Fujita et al found improved detectability of COPD in primary care settings using a hand-held flow meter regardless of the use of a symptom-based questionnaire. ${ }^{11}$ This may preclude the use of the screening questionnaire allowing screening of the population using PS alone. ${ }^{11}$ However, Franco-Marina et al, found that although the PS alone using a cut-off point of $\mathrm{FEV}_{1} / \mathrm{FEV}_{6}<0.80 \mathrm{had}$ a marginally better test performance, the sequential strategy had a sensitivity of $75 \%-80 \%$ and a specificity of around $85 \% .{ }^{17}$ Besides, the use of a screening questionnaire reduced the number of individuals who needed screening using spirometry. This is an important consideration in low resource settings like rural India, where health infrastructure is constrained. Based on the findings from our study, administration of the LFQ reduced the workload for CHWs related to conducting PS by about $60 \%$, increasing the feasibility and sustainability of a potential community-based screening program.

Some studies have reported on the accuracy of screening with a questionnaire in combination with a peak flow meter. ${ }^{22-25}$ However, the reliability of the peak flow meter in detecting COPD has been questioned. ${ }^{26}$ A systematic review conducted by Haroon et al found that PS is useful for COPD screening in primary care settings justifying its use in the current study. ${ }^{27}$

US Preventive Services Task Force did not find any conclusive evidence for the benefit or harm of screening asymptomatic adults with questionnaires or office-based spirometry. ${ }^{20}$ However, the GOLD guideline advocates the use of spirometry among those with symptoms and risk factors for early detection and the use of risk-score based screening questionnaires for screening in primary care settings. ${ }^{4}$ The evidence for the utilization of screening with questionnaires and PS as a preliminary detection or case-finding method is sparse, especially from LMICs. Implementation of spirometry requires its correct performance, reliable interpretation, and regular calibration of spirometers. ${ }^{28}$ These are very challenging criteria to meet especially in resource-constrained settings of LMICs like India, where the burden of COPD is high. Therefore, our study demonstrates a feasible approach to improve early detection and referral to ensure timely management, potentially resulting in improved disease outcomes. It also provides insights to obtain robust and reliable data to determine the actual COPD burden.

Currently, the National Programme for Prevention and Control of Diabetes, Cardiovascular Disease and Stroke (NPCDCS) in India, which also addresses the prevention and management of COPD, envisages that CHWs, ie, Accredited Social Health Activists (ASHA), will complete a score-based checklist, entitled Community Based Assessment Checklist (CBAC), through household visits. $^{29}$ The CBAC is supposed to be reviewed by an Auxiliary Nurse Midwife at a sub-centre (first point of contact for rural populations with non-physician health care providers in the Indian public health care system). Those with a high risk for non-communicable diseases (NCDs) are then referred to the primary health centre (first point of contact for rural populations with physician health care providers) for confirmation of the diagnosis and management. Our study has shown that CHWs can be trained to detect COPD at the community-level using a risk-score-based questionnaire and a pocket spirometer. However, underutilization of spirometry for the diagnosis of COPD, especially among physicians other than chest physicians in India, necessitates the strengthening of the infrastructure both in public and private health sectors to confirm diagnoses through spirometry. ${ }^{5}$ There is a need for further effectiveness and implementation research to assess the potential health benefits that can be achieved by this screening strategy for screening COPD at village level and sub-centre with subsequent linkage to the primary and secondary health care infrastructure for confirmation of diagnosis with post-bronchodilation spirometry for COPD management. 
To our knowledge, this is one of the first studies that assesses the diagnostic accuracy of utilizing CHWs to detect individuals with COPD using a screening questionnaire and PS in the community. However, increased detection of COPD should also be supported by strengthening the health systems to enable the confirmation of diagnosis and provision of timely guideline-based management, especially inhalational drugs in primary and secondary health care facilities.

This study had some limitations also. Due to limited resources, we could not perform our study on a larger sample, which limited the statistical power of the study to assess differences in the performance of individual CHWs in conducting PS. A few severe cases were missed by CHWs, however, all missed cases were participants who could not read or understand instructions clearly and it was thus difficult for the CHWs to coach these participants to perform the forced expiratory manoeuvres optimally. Additionally, we did not assess the exposure to the biomass fuel smoke as it was not part of the validated LFQ. Exposure to biomass fuel is one of the common risk factors for development of COPD especially among women in rural areas of LMICs. There is a need to develop a risk-score based screening questionnaire with a component of biomass fuel smoke exposure assessment and also assess its validity in detecting COPD.

\section{Conclusion}

In conclusion, undiagnosed COPD can be accurately identified by trained CHWs using a simple sequential screening strategy. This can potentially contribute to an accurate assessment of COPD burden and also to design tailored interventions for its effective management in rural India. More studies with a larger sample size in similar settings are required to further evaluate the feasibility, scalability, and sustainability of this sequential screening strategy to improve the early detection of COPD in low-resource settings.

\section{Acknowledgments}

This study was supported by a $\mathrm{PhD}$ scholarship grant under the Deakin India Research Initiative to Prashant Jarhyan. Prashant Jarhyan was also partly supported by the Public Health Foundation of India and by a VECD Global Health Fellowship, funded by the Fogarty International Centre (FIC) of the NIH (3D43TW00933709S3). The funders had no role in the design, conduct, analysis of the research or manuscript writing.

\section{Disclosure}

The authors report no conflicts of interest in this work.

\section{References}

1. Salvi S, Kumar GA, Dhaliwal RS, et al. The burden of chronic respiratory diseases and their heterogeneity across the states of India: the Global Burden of Disease Study 1990-2016. The Lancet Global Health. 2018;6(12):e1363-e74. doi:10.1016/S2214-109X(18) 30409-1

2. Lamprecht B, Studnicka M, Soriano J, et al. Heterogeneity in prevalence and underdiagnosis of COPD: results from BOLD, EPI-SCAN, PLATINO, and PREPOCOL. Eur Respir Journal. 2013;42.

3. Perez-Padilla R, Thirion-Romero I, Guzman N. Underdiagnosis of chronic obstructive pulmonary disease: should smokers be offered routine spirometry tests? Expert Rev Respir Med. 2018;12(2):83-85. doi:10.1080/17476348.2018.1419868

4. GOLD. Global strategy for the diagnosis, management and prevention of chronic obstructive pulmonary disease. 2020.Global Initiative for Chronic Obstructive Lung Disease. 2020 GOLD Reports. 2020 Global Strategy for the diagnosis, management and prevention of COPD. Available from: https://goldcopd.org/gold-reports. Accessed March November, 2020

5. Vanjare N, Chhowala S, Madas S, Kodgule R, Gogtay J, Salvi S. Use of spirometry among chest physicians and primary care physicians in India. NPJ Prim Care Respir Med. 2016;26. doi:10.1038/npjpcrm. 2016.36

6. Kaplan A, Thomas M. Screening for COPD: the gap between logic and evidence. Eur Respir Rev. 2017;26:143. doi:10.1183/160006 17.0113-2016

7. O'Donnell DE, Hernandez P, Kaplan A, et al. Canadian Thoracic Society recommendations for management of chronic obstructive pulmonary disease - 2008 update - highlights for primary care. Can Respir J. 2008;15 Suppl A:1a-8a. doi:10.1155/2008/641965

8. Kotz D, Nelemans P, van Schayck CP, Wesseling GJ. External validation of a COPD diagnostic questionnaire. Eur Respir J. 2008;31 (2):298-303. doi:10.1183/09031936.00074307

9. Dirven JAM, Tange HJ, Muris JWM, van Haaren KMA, Vink G, van Schayck OCP. Early detection of COPD in general practice: patient or practice managed? A randomised controlled trial of two strategies in different socioeconomic environments. Prim Care Respir J. 2013;22(3):331-337. doi:10.4104/pcrj.2013.00070

10. Stanley AJ, Hasan I, Crockett AJ, van Schayck OCP, Zwar NA. COPD Diagnostic Questionnaire. (CDQ) for selecting at-risk patients for spirometry: a cross-sectional study in Australian general practice. NPJ Prim Care Respir Med. 2014;24(1):14024. doi:10.1038/npjpcrm. 2014.24

11. Fujita M, Nagashima K, Takahashi S, Suzuki K, Fujisawa T, Hata A. Handheld flow meter improves COPD detectability regardless of using a conventional questionnaire: a split-sample validation study. Respirology. 2020;25(2):191-197. doi:10.1111/resp.13602

12. Swanney MP, Jensen RL, Crichton DA, Beckert LE, Cardno LA, Crapo RO. FEV6 is an acceptable surrogate for FVC in the spirometric diagnosis of airway obstruction and restriction. Am J Respir Crit Care Med. 2000;162(3):917-919. doi:10.1164/ajrccm.162.3.99 07115

13. Rao KD, Bhatnagar A, Berman P. So many, yet few: human resources for health in India. Hum Resour Health. 2012;10(19). doi:10.1186/ 1478-4491-10-19

14. Gupta AV, Phatak AG, Patel MU, et al. Effectiveness of a community health worker (CHW) training in monitoring and care of patients with chronic obstructive pulmonary disease (COPD) in rural Gujarat, India. J Family Med Prim Care. 2020;9(4):1910-1914. doi:10.4103/ jfmpc.jfmpc_1193_19 
15. Mohan S, Jarhyan P, Ghosh S, et al. UDAY: a comprehensive diabetes and hypertension prevention and management program in India. BMJ Open. 2018;8(6):e015919. doi:10.1136/bmjopen-2017-015919

16. Hanania NA, Mannino DM, Yawn BP, et al. Predicting risk of airflow obstruction in primary care: validation of the lung function questionnaire (LFQ). Respir Med. 2010;104(8):1160-1170. doi:10.1016/j. rmed.2010.02.009

17. Franco-Marina F, Fernandez-Plata R, Torre-Bouscoulet L, et al. Efficient screening for COPD using three steps: a cross-sectional study in Mexico City. NPJ Prim Care Respir Med. 2014;24:1400. doi:10.1038/npjpcrm.2014.2

18. Cohen JF, Korevaar DA, Altman DG, et al. STARD 2015 guidelines for reporting diagnostic accuracy studies: explanation and elaboration. BMJ Open. 2016;6(11):e012799. doi:10.1136/bmjopen2016-012799

19. Hanley JA, McNeil BJ. The meaning and use of the area under a receiver operating characteristic (ROC) curve. Radiology. 1982;143(1):29-36. doi:10.1148/radiology.143.1.7063747

20. Guirguis-Blake JM, Senger CA, Webber EM, Mularski RA, Whitlock EP. Screening for chronic obstructive pulmonary disease: evidence report and systematic review for the US preventive services task force. JAMA. 2016;315(13):1378-1393. doi:10.1001/jama.2016.2654

21. Sichletidis L, Spyratos D, Papaioannou M, et al. A combination of the IPAG questionnaire and PiKo- $6{ }^{\circledR}$ flow meter is a valuable screening tool for COPD in the primary care setting. Prim Care Respir J. 2011;20(2):184-189. doi:10.4104/pcrj.2011.00038

22. Nelson SB, LaVange LM, Nie Y, et al. Questionnaires and pocket spirometers provide an alternative approach for COPD screening in the general population. Chest. 2012;142(2):358-366. doi:10.1378/ chest.11-1474
23. Thorat YT, Salvi SS, Kodgule RR. Peak flow meter with a questionnaire and mini-spirometer to help detect asthma and COPD in real-life clinical practice: a cross-sectional study. NPJ Prim Care Respir Med. 2017;27 (1):32. doi:10.1038/s41533-017-0036-8

24. Mahboub B, Alzaabi A, Soriano JB, et al. Case-finding of chronic obstructive pulmonary disease with questionnaire, peak flow measurements and spirometry: a cross-sectional study. BMC Res Notes. 2014;7(1):241. doi:10.1186/1756-0500-7-241

25. Tian J, Zhou Y, Cui J, et al. Peak expiratory flow as a screening tool to detect airflow obstruction in a primary health care setting. Int $J$ Tuberc Lung Dis. 2012;16(5):674-680. doi:10.5588/ijtld.11.0429

26. Perez-Padilla R, Vollmer WM, Vázquez-García JC, et al. Can a normal peak expiratory flow exclude severe chronic obstructive pulmonary disease? Int J Tuberc Lung Dis. 2009;13(3):387-393.

27. Haroon S, Jordan R, Takwoingi Y, Adab P. Diagnostic accuracy of screening tests for COPD: a systematic review and meta-analysis. BMJ Open. 2015;5(10):e008133-e. doi:10.1136/bmjopen-2015-008133

28. Ho T, Cusack RP, Chaudhary N, Satia I, Kurmi OP. Under- and over-diagnosis of COPD: a global perspective. Breathe. 2019;15 (1):24. doi:10.1183/20734735.0346-2018

29. Directorate General of Health Services MoHFW, Government of India. National Program for Prevention and Control of Cancer, Diabetes, Cardiovascular Disease and Stroke 2016 [updated 03/ 08/ 2020. Available from: https://dghs.gov.in/content/1363_3_ NationalProgrammePreventionControl.aspx. Accessed March 13, 2021 .

\section{Publish your work in this journal}

The International Journal of COPD is an international, peer-reviewed journal of therapeutics and pharmacology focusing on concise rapid reporting of clinical studies and reviews in COPD. Special focus is given to the pathophysiological processes underlying the disease, intervention programs, patient focused education, and self management protocols. This journal is indexed on PubMed Central, MedLine and CAS. The manuscript management system is completely online and includes a very quick and fair peer-review system, which is all easy to use. Visit http://www.dovepress.com/testimonials.php to read real quotes from published authors. 